\title{
CONDIÇÃO HUMANA E EDUCAÇÃO EM HANNAH ARENDT
}

Odílio Alves Aguiar

\begin{abstract}
RESUMO
O artigo discute a relação entre condição humana e educação em Hannah Arendt. A autora é associada ao processo educativo da visão clássica da educação em contraposição à visão especializante e adestradora da modernidade. Em seguida, é apresentada a visão geral da condição humana em Arendt e, por último, aborda-se a natalidade que, segundo a autora em pauta, é a condição humana diretamente ligada à educação.
\end{abstract}

PALAVRAS-CHAVE: Condição humana. Educação. Natalidade. Hannah Arendt.

\begin{abstract}
This article is focused on Hannah Arendt's account of the relation between human condition and education. She will be portrayed as someone who favours the classical view of education as opposes the modern view of education based on specialization and dexterity. In addition to this, the general aspects of her conception of human condition will be outlined. The last part of this article will provide an account of Hannah Arendt's conception of natality as a human condition directly associated to education.
\end{abstract}

Keywords: Human condition. Education. Natality. Hannah Arendt.

* Professor Doutor do Departamento de Filosofia da Universidade Federal do Ceará. E-mail: odílio@uol.com.br 
Este ensaio pretende elucidar a afirmação de Hannah Arendt em "A Crise na Educação" que diz: "a essência da educação é a natalidade" ${ }^{1}$ A idéia é explicitar o tema da natalidade relacionando-o à posição da autora presente na obra $A$ Condiç̧ão Humana (1958) na qual a natalidade é, entre as demais condições, a mais intimamente ligada à capacidade de iniciar algo novo, isto é, à ação, pois "os homens, embora devam morrer, não nasceram para morrer, mas para começar". ${ }^{2}$

Hannah Arendt não privilegiou uma reflexão sobre a educação e, muito menos, sobre as práticas educativas. No entanto, a partir do texto "A Crise na Educação", que veio a lume na coletânea Entre o Passado e o Futuro (1961), podemos perceber que a educação foi incluída, explicitamente, nas suas reflexões sobre a crise inerente às sociedade modernas e contemporâneas. ${ }^{3}$ Convém ressaltar que essa reflexão insere-se na trilha aberta pelas grandes obras literárias e filosóficas ocidentais. Longe da postura modernista que associa educação a letramento, adestramento, controle e a especialização, mesmo quando associada à cidadania ou ao trabalho, Hannah Arendt vincula a educação à condição humana, seguindo, nesse aspecto, a intenção formadora presente nas obras clássicas de Homero, de Hesíodo, dos poetas trágicos, de Platão e Aristóteles, entre outros.

Evidentemente a concepção clássica de condição humana é profundamente marcada pela idéia de autoridade, de tradição e de narração. Essa visão foi estilhaçada pela crise moderna que se instalou no Ocidente, principal objeto da reflexão arend tiana desde Origens do Totalitarismo (1951).

Homero ao narrar a ira (ate) de Aquiles a atrela tanto à hybris - violência e isolamento desmesurado - quanto à imortalização conquistada a partir das lutas e das vitórias empreendidas com os seus companheiros e liderados. Aquiles retoma a sua trajetória

1 ARENDT, H. Entre o Passado e o Futuro, p. 223.

2 Idem. A Condição Humana, p. 258 (doravante CH no corpo do texto).

3 Sobre o tema da educação em Arendt, consultar o número 04, edição especial dedicada à autora, da Revista Educação, São Paulo: Editora Segmento, 2007. ISSN 1415-5486

Educ. e Filos., Uberlândia, v. 22, n. 44, p. 23-42, jul./dez. 2008. 
gloriosa ao sair da paralisação, do isolamento e do ressentimento causados pela atitude de Agamenon que lhe tomou a escrava Briseida. Sentindo-se desonrado por ter que devolver a filha de Crises, sacerdote do templo do deus Apolo, Agamenon exige a escrava de Aquiles, despojo de guerra, para demonstrar que ele é "o chefe e o maior rei entre todos". Trata-se da disseminação da discórdia (Éris) entre os amigos, geradora das "duas lutas": a destruição e a emulação. Aquiles é vítima da ação de Éris tanto pela hybris que provoca o seu isolamento e a sua crueldade para com Heitor morto - atraindo, assim, a ira dos deuses - quanto pela sustentação do agon, campo de batalha, pela destreza, pelo talento, pela palavra e pela força. A intenção formadora de Homero é profundamente agonista: trata-se da palavra e da força submetidas ao agon, à luta como o lugar do correto desaguar das energias provenientes de Éris. Homero, assim, simboliza, paradigmaticamente, a associação entre condição humana e emulação - competição pela excelência (areté) - entre viver e lutar.

Hesíodo, especialmente em Os Trabalhos e os Dias, também apresenta uma intenção formadora direcionada ao tema da condição humana. Alertando seu irmão Perses, com o qual está em litígio por conta da divisão da herança paterna, o autor abre a obra admoestando para "as duas lutas". Segundo ele, os frutos da boa Éris, entre os humanos, são: trabalho, arte, riqueza e fartura; e são frutos da má Éris: guerra, morte, assassinato, fome, fadiga e escravidão. Hesíodo chama-nos atenção para o trabalho (ergon) e para a justiça (diké) como dimensões intimamente relacionadas à condição humana, nem divina nem animal, do homem ${ }^{4}$.

Se Homero é o poeta da ligação entre condição humana e luta e Hesíodo é o aedo da vinculação entre condição humana e trabalho, Édipo Rei é a narrativa que reúne pulsão sexual e condição humana, pelo menos na interpretação da escola freudiana. A circunscrição da sexualidade ao campo da dizibilidade, isto é, do laço social, da interdição ao incesto e dos poderes destrutivos

4 Esse aspecto foi muito bem ressaltado por Mary de Camargo Neves Lafer na sua tradução de Os Trabalhos e os Dias, publicado pela Editora Iluminura, 1989. 
inerentes à pulsão sexual é o que vem à tona no mito edipiano. Em Édipo Rei, Sófocles sinaliza a renúncia à ilimitação (hybris) da pulsão e sua passagem à sexualização e à limitação em vista da permanência e continuidade da comunidade.

Passemos, agora, ao exame da idéia arendtiana de condição humana. Para entendermos essa categoria iremos associá-la, por analogia, ao conceito de lugar exposto por Aristóteles na sua obra Física. Essa analogia é de grande valia heurística, não só porque esse autor é muito caro a Hannah Arendt, mas, também, porque temos nesse autor a mais nítida consciência da união entre formação e condição humana como possibilidade do florescimento dos homens. Aristóteles é, além do mais, sem dúvida alguma, herdeiro da tradição homérica e trágica da cultura grega ${ }^{5}$. A centralidade da categoria areté (excelência), assim como eudaimonia, phronimos e phronesis, entre outras, de reconhecida proveniência homérica e trágica, sinalizam a relação entre educação e condição humana nesse autor.

Aristóteles inicia o capítulo primeiro, do livro quarto, da "Física", dizendo que "todo mundo crê, com efeito, que os seres que existem estão em algum lugar, pois o não-ser não está em nenhuma parte" (PH, IV, 208b) ${ }^{6}$. Em seguida, diferencia lugar comum de lugar próprio: "existe um lugar comum: aquele em que existem todos os corpos; e existe um lugar próprio, aquele em que existe um ser determinado" (PH, IV, 208b). O lugar (topos) é, assim, "o que primeiro e imediatamente contém cada um dos seres corporais, uma espécie de limite do corpo circundante" (PH, IV, 2008b). O lugar comum contém todos os corpos e o lugar próprio, situado no lugar comum, contém um ser determinado.

5 Cf. de MACINTYRE, Alasdair: "Justiça e ação na imaginação homérica". In Justiça de quem, qual racionalidade? São Paulo: Loyola, 1991, p. 23-39; AUBENQUE, Pierre: "A fonte trágica". In A Prudência em Aristóteles. São Paulo: Discurso, 2003, p. 245-281 e de JAEGER, Werner: Paideia, (especialmente os primeiros capítulos que abordam a tradição homérica e trágica), Brasília: UNB, 1989.

6 ARISTOTELES. "Physics". In The Basic Works of Aristotle, New York: The modern library, 2001(abreviada no corpo do texto como PH. Tradução nossa).

Educ. e Filos., Uberlândia, v. 22, n. 44, p. 23-42, jul./dez. 2008. 
Esta definição se faz presente, também, na Metafísica quando, discutindo a respeito do ser e não-ser, Aristóteles diz que lugar é o campo onde o ser realiza a passagem da potência (dynamis) ao ato (energeia) e no texto sobre as Categorias diz que lugar pertence à categoria de quantidade, afirmando aí que um corpo sempre ocupa um lugar no espaço e é, no intervalo do lugar, que o corpo se posiciona no espaço. ${ }^{7}$ Essa concepção da categoria de lugar reenvia à sua interpretação canônica na qual é entendida como extensão tridimensional, ou seja, "o lugar possui, certamente, as três dimensões: latitude, longitude e altura" e é a esfera que contêm o corpo circundante: "espaço receptivo entre limites extremos" $(\mathrm{PH}$, IV , 209a), ou ainda: "o lugar é o limite imóvel primeiro e imediato do continente" (PH, IV, 209b). A esfericidade, a tridimensionalidade do lugar, remete à idéia aristotélica de que fora da última esfera só existe o vazio, entendido como limite do corpo ausente. É nas esferas (terra e universo), segundo Aristóteles, que o ser pode se realizar. Além da última esfera, só existe o éter, o vazio. O lugar contém o ser contido, mas não é idêntico a ele, não é, assim, uma substância, uma causa produtora do ser contido, mas um espaço onde o ser pode realizar o seu movimento (kinesis). Para Aristóteles, cada ser possui um lugar para realizar a sua forma e finalidade. Os corpos buscam realizar o seu ser natural no seu lugar natural. Esse lugar faz parte da entelechia que realiza a potência própria de um ser. Sem lugar próprio no lugar comum, a transição da potencialidade (dynamis) ao ato (energeia) fica inviabilizada. O movimento (kinesis), entendido por Aristóteles como mudança, geração e corrupção do ser, necessita do lugar para acontecer. O lugar, dessa forma, não é uma substância em si, não é a causa do movimento, mas condição para ordenar a passagem da potência ao ato.

Essa idéia de lugar (topos) facilita a aproximação entre a idéia de contingência, âmbito do humanamente possível, em Aristóteles,

7 Cf. a respeito de ARISTÓTELES, Metafísica, 3 vols, São Paulo: Paulus e de PORFÍRIO de Tiro "Isagoge": Introdução às Categorias de Aristóteles, São Paulo: Attar editorial, 2002. 
e a concepção que emergirá da condição humana na obra arendtiana. Como uma espécie de "lugar", a condição humana não indica determinação, mas modo de ser, condição de possibilidade para o florescimento humano (eudaimonia). O "lugar" não determina a identidade do corpo presente no seu espaço. A polis não determina a identidade do cidadão, mas fornece um espaço apropriado para que ele revele quem é. Na mesma linha, podemos remeter à categoria de assuntos humanos no início das obras Ética a Nicomaco e Política de Aristóteles. Logo no início do Livro I da Ética a Nicômaco, ao abordar os assuntos políticos, diferencia-os dos assuntos metafísicos, diz que esses partem dos princípios primeiros e aqueles partem dos fatos (EN, 1095b1103a) ${ }^{8}$. Partindo desse tema, realiza uma demorada discussão a respeito do Bem e da Felicidade, questões pertencentes, exclusivamente, ao âmbito humano. Ao tratar da Phroairesis, da deliberação, no livro III, ao se perguntar a propósito do que pode o homem deliberar, Aristóteles afirma que acerca das coisas eternas, ninguém delibera: "deliberamos sobre as coisas que estão ao nosso alcance e podem ser realizadas" (EN, 1112, 30), pois o princípio motor está em nós mesmos. Para o estagirita, existem coisas pertencentes à ordem do possível e, outras, à necessidade. A condição humana é o campo no qual se realizam as deliberações humanas, onde o que ocorre pode acontecer de formas diversas e não como espaço de realização do necessário, do eterno e do imutável. ${ }^{9}$ Na obra Política, em vez de seguir o mestre Platão na sua República ideal, Aristóteles inicia sua pesquisa analisando a formação e a constituição político-jurídica das diversas cidades do seu tempo. Esse procedimento, para Aristóteles, é a maneira de escapar do necessitarismo da perspectiva teórica, pois os assuntos humanos são atravessados pelas paixões e pelas deliberações dos homens e não determinados por um padrão ideal. Isso não significa que tudo seja possível. Para o estagirita, os negócios humanos visam

8 EN é abreviação para Ética a Nicômaco, Editora Abril, Coleção Pensadores.

9 Cf. a respeito de Chaui, Marilena o item "A peculiaridade da ação humana" in Introdução à História da Filosofia, São Paulo: Companhia das Letras, 2002, p. 443.

Educ. e Filos., Uberlândia, v. 22, n. 44, p. 23-42, jul./dez. 2008. 
à felicidade (eudaimonia) e esse telos se realiza nos desejos e nas deliberações mediadas pelo princípio racional e outros limites favoráveis à manifestação da humanidade dos homens, assim como, a sua transgressão ou destruição, podem acarretar a autodestruição.

A relação entre educação e condição humana, nessas posições clássicas, é propícia ao florescimento humano, entendido como desenvolvimento das capacidades poiéticas, teóricas e práticas. Sem trabalho, agon, educação, Polis e arte, o homem reduz-se a mero ser vivente (dzoé). A condição humana funciona como uma espécie de habitat apropriado ao desabrochamento e revelação dos seres humanos (bios).

Se, na tradição literária e filosófica clássica, a educação relaciona-se à condição humana, a tendência a romper com essa condição prevalece no experimentalismo científico, na técnica, na economia, na política e nas demais instituições surgidas na modernidade. O mundo moderno nasce e se mantém sob a égide da ruptura e da crise. O paroxismo dessa tendência, encontramos, segundo Arendt, no totalitarismo. Na Éris moderna, vai imperar a hybris do domínio total, a proibição a qualquer emulação. ${ }^{10}$ Esta categoria é convocada, em Origens do Totalitarismo, para compreender a especificidade de uma instituição governamental completamente nova. $\mathrm{O}$ totalitarismo foi uma forma de governo que, pelo fato de rejeitar a política, se diferenciou de todas as outras, inclusive do despotismo e da tirania. Sua novidade radical residiu na tentativa de fabricar um tipo exclusivo de homem e, assim, na rejeição da condição humana da pluralidade: "o fato de não o homem, mas os homens habitarem a terra". A mais alta realização do domínio total, nas experiências totalitárias, foram os campos

${ }^{10} \mathrm{O}$ termo hybris do homem moderno, cujo sentido está presente em toda obra arendtiana, aparece pela primeira vez no artigo "O que é a filosofia da Existenz? Escrito originalmente em 1946, este artigo é perpassado por um tom polêmico e faz o elogio a Jaspers em detrimento do pensamento de Heidegger, no qual o Eu, na linha das modernas filosofias da consciência, vem concebido como "Senhor do Ser", situado no lugar de Deus. Cf. a respeito in A Dignidade da Política, p. 15-37. 
de concentração, onde se conjugam, de maneira mortal, crime governamental e tecnologia.

Embora ocupada em compreender o totalitarismo como forma de governo, Arendt encontra, na composição categorial da modernidade, outros elementos que passaram a afetar a condição humana, desde a tentativa de fabricar e de prolongar a vida até as questões provenientes da redução do conhecimento a know-how; o progresso tecnológico, especialmente a automação; o divórcio entre conhecimento e pensamento; e a compreensão da linguagem apenas como signo lógico-matemático, mathesis universalis, entre outros.

A partir de A Condição Humana, é perceptível que o ethos modernista se pauta na ambição do domínio para além da natureza terrestre e das organizações humanas. Isso fica patente no primeiro parágrafo do livro, no qual está escrito:

Em 1957 um objeto terrestre, feito pela mão do homem, foi lançado ao universo, onde durante algumas semanas girou em torno da Terra segundo as mesmas leis de gravitação que governam o movimento dos corpos celestes - o Sol, a Lua e as estrelas. É verdade que o satélite artificial não era nem lua nem estrela; não era um corpo celeste que pudesse prosseguir em sua órbita circular por um período de tempo que para nós, mortais limitados no tempo da Terra, durasse uma eternidade. Ainda assim, pôde permanecer nos céus durante algum tempo; e lá ficou, movendo-se no convívio dos astros como se estes o houvessem provisoriamente admitido em sua sublime companhia (CH, p. 9).

Arendt vai interpretar o posicionamento do satélite na órbita celeste, não apenas em termos de força, poder e domínio humano, mas, principalmente, como "o primeiro passo para libertar o homem de sua prisão na terra", isto é, em termos de ruptura com a condição humana. A conjugação entre ruptura com a condição humana e a tentativa de dominar, de forma total, a natureza, o próprio homem e o universo é a novidade que podemos extrair desta obra de Arendt. A questão é que a antiga tendência à hybris, antes pensada em termos de desmesura da força, da inveja, do

Educ. e Filos., Uberlândia, v. 22, n. 44, p. 23-42, jul./dez. 2008.

30 
orgulho e da soberba, tematizada pela filosofia e pela literatura, é agora realização da ficção científica. Esta, segundo Arendt, é o "veículo dos sentimentos e desejos das massas" ( $\mathrm{CH}$, p. 10), na forma da completa artificialização da vida, na emancipação de todos os limites que antes prendiam o homem à condição humana. Sobre isso afirma a autora: "O progresso científico e as conquistas da técnica serviram apenas para realização de algo com que todas as eras anteriores sonharam e nenhuma pode realizar" $(\mathrm{CH}, \mathrm{p} .12)$. O resultado, porém, não é o aumento da dignidade do homem, mas o seu apequenamento e impotência, como bem anota a autora no belíssimo texto "A Conquista do Espaço e a Estatura Humana", presente em Entre o Passado e o Futuro.

A pretensão de domínio total, cuja expressão máxima é o campo de concentração, conjuga o elevado formalismo e artificialismo com a tendência à naturalização da sociedade: violência, massificação, propaganda, miséria e laborização das atividades humanas. Sem lugar para a excelência e a luta agônica, cada vez mais a vida vai perdendo sua possibilidade de realização qualificada, de se expressar em atos e palavras, e reduzindo-se a função vital, vê-se em situação de descartabilização. É em função dessa tendência que Arendt vai ampliar a idéia de condição humana. Se na tradição, como vimos, a ruptura com a condição humana era localizada e relacionada a uma desmedida específica que separava o indivíduo da comunidade, na modernidade, a ruptura tem um alcance muito maior, pois apresenta o perigo da descartabilidade do humano nas suas qualidades próprias.

Por essa razão, Arendt vai conceber a terra, a natalidade, o mundo, a linguagem e a pluralidade como condições da vida humana e, assim procedendo, está pensando um caminho que favoreça a realização humana da espécie humana de forma espontânea, da mesma forma como a sua alteração ou a sua ruína pode levar à destruição do próprio homem. A tendência à vida tecnificada, na qual a técnica não é apenas meio, mas erguida em fim em si mesma, geradora da mentalidade estratégica e artificialista, faz com que as formas espontâneas da vida humana percam seu lugar próprio para se manifestar num mundo comum. 
A expressão condição humana não deve nos levar, porém, a uma interpretação metafísica, como se as atividades que nela se realizam devessem se realizar de uma forma única e para todo o sempre, tal qual entenderam os opositores da reflexão arendtiana. ${ }^{11}$ A interpretação metafísica de Arendt está diretamente relacionada à recepção de seus escritos sobre o totalitarismo. ${ }^{12}$ Os teóricos que abordavam esse assunto eram imediatamente enquadrados como autores liberais. Para outros, Arendt era uma autora a-histórica ou irracionalista, pré-modernista, pois fazia uma tematização do trabalho, da fabricação e da ação, relacionando-as à idéia de condição humana. ${ }^{13}$ Entendiam que essas categorias, na autora, eram eternas, e as sociedades, quaisquer que fossem, teriam que se estruturar hierarquicamente entre os homens que trabalham, fabricam e agem, cabendo aos trabalhadores o mesmo lugar dos escravos nas sociedades escravistas. Arendt foi, por isso, posta entre os liberais, reacionários e tradicionalistas. Eles não entendiam que ela estava dizendo que o homem, para viver, precisa sempre dar conta da vida e da sua reprodução; de um mundo que o proteja das intempéries da natureza e de um espaço que possibilitasse a sua interação política e linguisticamente mediada. Não há aí nenhuma receita de como os homens devem cuidar da sua reprodução biológica, da terra, do mundo e da esfera pública. A condição humana é compreendida pela vita activa e pela a vida do espírito e não é entendida substancialmente: não se trata de uma essência que determina todos os seres predicados por ela, pois não define um conteúdo, trata-se, antes das condições nas quais o ser humano pode viver e se realizar. Agir e pensar são capacidades que se realizam em determinadas circunstâncias, mas essas

${ }^{11}$ Podemos apontar aqui Georg Lukács em El asalto a la Razón (1959) e, mais recentemente, Luc Ferry nos seus três tomos de Philosophie Politique (1984).

12 Cf. MONGIN, Oivier. "La réception d'Arendt em France". In Ontologie et Politique, Paris: Tierce, 1993, p. 7-13.

${ }^{13}$ Sobre a tradução de labor, work e action por trabalho, fabricação e ação cf. o artigo de Teresa Calvet, "O Trabalho (labor) em Hannah Arendt". In Ensaio, ${ }^{\circ}$ 14, p. 131-168, 1985.

Educ. e Filos., Uberlândia, v. 22, n. 44, p. 23-42, jul./dez. 2008.

32 
circunstâncias jamais determinam o conteúdo da ação e do pensamento.

Essa linha de raciocínio corrobora com a diferença entre condição e natureza humana exposta por Arendt no primeiro capítulo de A Condição Humana. Diz ela: "Para evitar erros de interpretação: a condição humana não é o mesmo que a natureza humana, e a soma total das atividades e capacidades humanas que correspondem à condição humana não constituem algo que se assemelhe à natureza humana" $(\mathrm{CH}, \mathrm{p}$. 18). Isso fica mais claro quando, logo a seguir, no mesmo contexto, Arendt afirma que

Éaltamente improvável que nós, que podemos conhecer, determinar e definir a essência natural de todas as coisas que nos rodeiam e que não somos, venhamos a ser capazes de fazer o mesmo a nosso próprio respeito. (...) Em outras palavras, se temos uma natureza ou essência, então certamente só um deus pode conhecê-la e definila; e a condição prévia é que ele possa falar de um "quem" como se fosse um "que" (CH, p. 18-19).

Quando o assunto sobre o qual estamos falando é o homem, não podemos fazê-lo da forma predicativa. A humanidade do homem não é algo definível teoricamente. Trata-se de acontecimentos que se manifestam nas suas ações, palavras, pensamentos e obras. O ser-próprio de um homem, o seu "quem", só se revela quando dele se conta a história, os feitos e as palavras. $\mathrm{O}$ "quem" é a pessoa.

É importante frisar isso a fim de que não sucumbamos a uma visão estética ou religiosa da dignidade humana, isto é, na concepção que a reduz às obras que os homens produzem ou a uma alma imortal. Dignidade humana só pode ser pensada em relação com a estatura do homem no mundo, sua importância, seu lugar e seu valor. Todavia, em momento algum, isso significa que o homem seja o fim último da criação, senhor da natureza e da sociedade. Para surgir, o "quem" necessita da liberdade enquanto característica da condição humana, cujo sentido não é o distanciamento de uma condição escrava, superada por uma condição soberana, de autonomia absoluta. Trata-se da liberdade 
no sentido de "amor mundi", da disposição de agir e de se interessar por algo que não é da ordem da posse e, sim, do mundo comum sobre o qual o homem não tem controle algum.

Quando Arendt menciona a categoria condição humana, está se referindo às condições da existência humana, tais como: "a vida, a natalidade e a mortalidade, a mundanidade, a pluralidade e o planeta Terra" (CH, p.19), entendidas como uma espécie de lugar, ambiente onde os seres humanos realizam-se e executam suas atividades. Segundo Arendt, a condição humana não condiciona e nem explica quem somos. Desse modo, a condição humana é o campo no qual os humanos decidem os seus destinos e, por não estar determinada uma vez por todas, não pertence à esfera dos assuntos eternos e, sendo atravessada pela deliberação e pela contingência, o que aí acontece poderia não acontecer.

Essas condições, evidentemente, não fabricam o conteúdo, o homem, contudo viabilizam ou obstruem o aparecimento do seu ser-próprio: sua humanidade. Nascer, existir, habitar a terra e suportar a inevitabilidade da morte são condições recriadas pelas atividades do trabalho, da fabricação, da ação e do pensamento. Por intermédio dessas últimas, as necessidades vitais são amenizadas e recuam no seu teor coercitivo; o mundo surge como lugar de proteção e a terra pode ser embelezada; e, assim, por meio da ação e do que ela funda, tudo se conjuga para a garantia da continuidade histórica. Ao tentar fugir desses limites, o homem pode realizar o impossível ou inimaginável, mas ao preço de perderse a si mesmo.

Para entendermos o sentido da idéia arendtiana de condição humana, cumpre, ainda, observar a diferença entre mankind e humaness, entre espécie humana e humanidade, exposta no texto sobre Lessing em Homens em Tempos Sombrios. ${ }^{14}$ A humanidade do homem não possui uma receita mensurável da mesma forma que o trabalho (labor) garante a reprodução do homem enquanto espécie animal. A dimensão humana do ente humano realiza-se

${ }^{14}$ Cf. idem, Homens em Tempos Sombrios, p. 30 e 31.

Educ. e Filos., Uberlândia, v. 22, n. 44, p. 23-42, jul./dez. 2008.

34 
na medida em que ele se singulariza num "quem" que surge e vive espontaneamente nos limites dados pela condição humana: terra, mundo (linguagem) e pluralidade. Na atualidade, vários autores, estudiosos da ética, estão preocupados com a sobrevivência da espécie humana na terra, pelas seguintes razões: expansão tecnológica em direção à vida (biogenética); destruição do meioambiente; desenvolvimento e poderio bélico; opressão econômica, geradora da miséria e fome no mundo. Todos esses pontos, e outros não elencados, apontam para a idéia de que emancipação humana não se coaduna com a cisão em relação à natureza e todos os outros limites dados à existência do homem na terra. Essa tendência, cujo rompimento com a condição humana remete a uma idéia de natureza humana a ser fabricada, é um resquício proto-totalitário presente nas sociedades e culturas contemporâneas. A não aceitação da condição humana é uma hybris, cujo resultado é a destruição, a violência, a guerra, a tirania, a manipulação, a exploração etc. Fabricar a vida, transformar o espaço público, lugar da espontaneidade humana, em espaço midiático, onde a encenação política, a visibilidade, converte-se literalmente em ficção e espetacularização, mostra-nos que os homens pouco aprenderam com as experiências e que a dificuldade de aceitar a condição humana está em plena atividade em nossos dias.

Arendt recebe, do clima intelectual hegemônico, após a Primeira Guerra Mundial, a interrogação do direcionamento cientificista e laborista da vida e a colocação em discussão a respeito do sentido trágico, finito, da existência e dos males para a humanidade provenientes das tentativas de rompimento com a condição humana. Esses temas foram apresentados principalmente pelos expoentes da fenomenologia. Ao abordá-los, no entanto, Arendt não fala de vida autêntica, originária, cuja possibilidade concreta só pode se dar ao preço do rompimento da comunicação com os outros e da renúncia ao mundo comum, como chama atenção no texto "O que é a filosofia da Existenz?" Há, sem dúvida alguma, um viés fenomenológico em $A$ Condição Humana. No entanto, isso tem que ser muito bem compreendido, pois a afirmação da ação e da natalidade, isto é, da comunicação e da 
esperança na re-fundação do mundo comum, em nada se assemelha a uma perspectiva que se fecha na morte e na angústia como os elementos que norteiam a condição humana. Ao mesmo tempo, apresenta a interação linguísticamente mediada dos homens como o aspecto da crítica ao homem moderno capaz de recuperar o sentido do respeito à natureza, à vida e à cultura, conforme escreveu a autora: "para que venha a ser aquilo que o mundo sempre se destinou a ser - uma morada para os homens durante sua vida na terra - o artifício humano deve ser um lugar adequado à ação e ao discurso" (CH, p. 187).

Se, até agora, fizemos uma apresentação geral da idéia arendtiana de condição humana e sua íntima ligação com a tentativa de compreender o seu momento histórico, daqui para frente, iremos explicitar mais a sua idéia de natalidade, até mesmo para fazer jus à relação feita pela autora entre natalidade e educação. Evidentemente quando refletimos sobre a condição humana em Arendt, ficou manifesto, na parte anteriormente exposta, que se trata de reunir elementos e aspectos que convergem e culminam na natalidade. Para Arendt, o homem é um ser-parao-nascimento. A natalidade é a instância crítica capaz de questionar a descartabilização dos homens nos campos de concentração. Mas esse conceito possui um valor heurístico de alcance muito maior, pois é capaz de expor a radicalidade do mal presente numa sociedade com pretensão de domínio e controle total sobre a vida, a cultura, os laços sociais etc. Essa sociedade, mesmo quando não está submetida ao tacão do governo totalitário, pode seguir suas sendas ao eliminar a possibilidade de inserção espontânea dos homens no mundo comum. A capacidade da esfera econômica de controlar os campos possíveis das ações e das interações humanas, através da mediação cibernética, da biogenética ou do biopoder, coloca-se na trilha aberta pelas experiências totalitárias e dirige-se ao homem como mero ser natural, manipulável e intercambiável.

Arendt reconhece a tendência à ruptura com a condição humana no artificialismo do mundo contemporâneo, por isso mesmo vai afirmar a importância da natalidade. Obviamente, ela não está fazendo a defesa da vida qua vida biológica. Arendt não

Educ. e Filos., Uberlândia, v. 22, n. 44, p. 23-42, jul./dez. 2008.

36 
é uma autora situada no campo da bioética, não segue a tendência dessa corrente na defesa da vida em geral. Embora a natalidade, discutida por ela, sustente-se numa vida biologicamente constituída, trata-se, exatamente do contrário: de questionar toda tentativa de reduzir o homem a mera função vital, controlável e supérflua. A categoria de natalidade, em Arendt, é uma aposta esperançosa na capacidade humana de agir e de falar, de romper qualquer tentativa de opressão, manipulação e controle. Por essa razão, colocamos a reflexão, da nossa autora, na trilha aberta pelos clássicos que abordaram explícita ou implicitamente a relação entre ação, fala e condição humana.

Se as experiências recentes, entre as quais, os campos de concentração, apresentam pretensões inusitadas e rompimentos radicais em relação à tradição e à autoridade do passado, balizadoras do pensamento e do comportamento humano, ao expor a categoria de natalidade, Arendt quer dizer que, apesar dessa ruptura, não só é possível o homem continuar agindo, mas que somente ações originárias, fundadoras e revolucionárias poderão trazer à luz novas condições, instituições, um mundo comum e dotar o homem de um "lugar" que favoreça o seu florescimento e a revelação das suas qualidades especificamente humanas.

Desse modo, para além da crítica ontológica à modernidade, há, em Arendt, uma dimensão ético-política que é fundamental. Isto é, o respeito à natureza, à vida e à cultura só tem sentido se propiciarem um espaço de aparição onde o agente possa mostrar "quem" é e, assim, sejam preservadas sua capacidade de agir e de falar livremente. Mesmo que não haja, atualmente, respeito à condição humana, não há pessimismo em Arendt, pois permanecem, como potencialidades, as faculdades humanas de iniciar e, com elas, a esperança. A esse respeito, escreve arendt:

[...] fluindo na direção da morte, a vida do homem arrastaria consigo, inevitavelmente, todas as coisas humanas para a ruína e destruição, se não fosse a faculdade humana de interrompê-las e iniciar algo novo, faculdade inerente à ação como perene advertência de que os homens, embora devam morrer, não nasceram para morrer, mas para começar $(\mathrm{CH}$, p. 258).

Educ. e Filos., Uberlândia, v. 22, n. 44, p. 23-42, jul./dez. 2008. 
A contraposição à hybris modernista, dessa forma, não se fecha numa idéia de reapropriação do si mesmo do homem, nem do seu trabalho alienado ou qualquer outro tipo de solução que se pauta na afirmação da soberania dos homens, uma vez que, "a impossibilidade de permanecerem como senhores únicos do que fazem, de conhecerem as conseqüências de seus atos e de confiarem no futuro é o preço que pagam pela pluralidade e realidade, pela alegria de conviverem com outros num mundo cuja realidade é assegurada a cada um pela presença de todos" (CH, p. 256).

Muitos são os obstáculos à constituição do mundo comum e da linguagem como lugar próprio aos humanos, no entanto, apesar dos estorvos, a ação mantém seu poder de fundação e de lugar apropriado à liberdade humana. Isso significa que toda e qualquer solução proposta passa pelo respeito à condição humana, pois, sem considerá-la, o homem poderá alcançar muitos objetivos, mas decairá em estatura, posto que estarão perdidas as condições nas quais a sua humanidade poderá vicejar e aparecer.

Assim, composta pela terra, mundo, linguagem, pluralidade e mortalidade, a condição humana, em Arendt, recebe a arrematação na natalidade, cujo sentido reside na passagem do homem como membro da espécie e, enquanto tal, mudo e determinado, para um ser que rompe o seu círculo funcional e manifesta-se espontaneamente como um ser singular na linguagem e na ação.

Essa distinção singular - diz Arendt - vem à tona no discurso e na ação. Através deles, os homens podem distinguir-se, ao invés de permanecerem apenas diferentes; [...] são os modos pelos quais os seres humanos se manifestam uns aos outros, não como mero objetos físicos, mas enquanto homens. Essa manifestação, em contraposição à mera existência corpórea, depende da iniciativa, mas trata-se da iniciativa da qual nenhum ser humano pode absterse sem deixar de ser humano ( $\mathrm{CH}$, p. 189).

Há aí um posicionamento em direção a uma ética da singularização distante da postura universalista, normatizadora, infinitista. Trata-se de aceitar que os homens carregam consigo poderes inaugurais, pois são capazes de realizarem, por eles

Educ. e Filos., Uberlândia, v. 22, n. 44, p. 23-42, jul./dez. 2008.

38 
mesmos, ações, palavras e pensamentos. O homem não é apenas imitação e repetição, mas capacidade de, no interior da condição humana, começar algo e, dessa forma, inserir-se no mundo humano.

Esta inserção - escreve Arendt - é como um segundo nascimento, no qual confirmamos e assumimos o fato original e singular do nosso aparecimento físico original. Não nos é imposta pela necessidade, como o labor, nem se rege pela utilidade, como o trabalho. Pode ser estimulada, mas nunca condicionada, pela presença dos outros em cuja companhia desejamos estar; seu ímpeto decorre do começo que vem quando nascemos, e ao qual respondemos começando algo novo por nossa própria iniciativa (CH, p. 189-190).

Abordar esse conceito de natalidade e suas implicações no universo pedagógico-educacional, é muito difícil, posto que as exigências científico-metodológicas, ideológicas e de mercado tem sobredeterminado o universo da formação. Retomar a perspectiva arendtiana a propósito da educação significaria: estimular, para usar o termo da autora, nos nossos jovens, o espírito da emulação e da excelência, onde vigora a produtividade, a competição econômica e a funcionalização das atividades humanas; impulsionar o respeito aos outros num contexto de naturalização das relações humanas, num mundo, onde a palavra não tem nenhum valor e as relações humanas estão assentadas em imagens e outros meios virtualizadores; convidar ao respeito à natureza e à terra, onde a tendência artificialista predominante tende a reduzir os homens a genes; provocar as capacidades fundadoras nos homens, onde o progresso retira e destrói qualquer idéia de permanência; investir numa educação que valorize a Beleza, embora o lugar da arte nas sociedades contemporâneas tenha sido usurpado pelo entretenimento; significaria, por fim, incentivar o compartilhamento do mundo com os outros, numa situação de solidão generalizada e de busca pela riqueza e pelo consumo como a solução de todos os problemas.

Como viabilizar pedagogicamente isso? Eis o grande desafio.

Educ. e Filos., Uberlândia, v. 22, n. 44, p. 23-42, jul./dez. 2008. 


\section{Referências}

ARENDT, Hannah. Origens do Totalitarismo. Tradução de Roberto Raposo. São Paulo: Companhia das Letras, 1990.

A Condição Humana. Tradução de Roberto Raposo. Rio de Janeiro: Forense, 1983.

Entre o Passado e o Futuro. Tradução de Mauro Barbosa de Almeida. São Paulo: Perspectiva,1988.

Da Revolução. Tradução de Fernando Dídimo Vieira. São Paulo: Ática-Unb, 1990.

Homens em Tempos Sombrios. Tradução de Denise Bottmann. São Paulo: Companhia das Letras, 1987.

Sobre a Violência. Tradução de André Duarte. Rio de Janeiro: Relume/Dumará, 1994.

- Crises da República. Tradução de José Volkmann. São Paulo: Perspectiva, 1973.

A Vida do Espírito. Tradução de Antônio Abranches et al. Rio de Janeiro: Relume/Dumará-UFRJ, 1992.

Lições sobre a Filosofia Política de Kant. Tradução de André Duarte. Rio de Janeiro: Relume/Dumará, 1993.

A Dignidade da Política. Coletânea organizada e traduzida por Antonio Abranches et al. Rio de Janeiro: Relume-Dumará, 1993.

ARISTOTLE. "Physica" in The Basic Works of Aristotle, New York: The Modern Library, 2001.

ARISTOTELES. Metafísica. Tradução de Marcelo Perine. São Paulo: Paulus, 2003.

Educ. e Filos., Uberlândia, v. 22, n. 44, p. 23-42, jul./dez. 2008.

40 
Ética a Nicômaco. Col. Pensadores. Trad. Gerd Borheim. São Paulo: Abril, 1979.

AUBENQUE, Pierre. A Prudência em Aristóteles. São Paulo: Discurso, 2003.

CASSIN, Barbara. Ensaios Sofísticos. Tradução de Ana Lúcia de Oliveira e Lúcia Cláudia Leão. São Paulo: Siciliano, 1990.

CHASIN, José. Sobre o Conceito de Totalitarismo, in TEMAS, Vol. 1, São Paulo: ed. Grijalbo,1977.

CHAUI, Marilena. Introdução à História da Filosofia, São Paulo: Companhia das Letras, 2002.

FERRY, Luc. Philosophie Politique (3 vols.), Paris: PUF, 1984.

JAEGER, Werner. Paidéia, Brasília: UNB, 1989.

HESÍODO. Os Trabalhos e os Dias. Tradução de Mary de Camargo Neves Lafer. São Paulo: Iluminuras, 2006.

HOMERO. A Ira de Aquiles. Tradução de Haroldo Campos. São Paulo: Nova Alexandria, 2000.

Arx, 2003

A Ilíada (2 vols.). Tradução de Haroldo Campos. São Paulo:

LUKÁCS, Georg. El Asalto a la Razón. México: Fondo de Cultura Econômica, 1959.

MACINTYRE, Alasdair. Justiça de quem, qual racionalidade? São Paulo: Loyola, 1991.

MONGIN, Olivier. "La réception d'Arendt em France". In Ontologie e Politique, Paris, Tierce, 1989. 
REVISTA EDUCAÇÃO. São Paulo. No 04. Editora Segmento, 2007.

ROVIELLO, Anne-Marie. Sens Commun et modernité chez Hannah Arendt. Paris: Ousia, 1987.

SÓFOCLES. Édipo Rei. Tradução de Paulo Neves. Porto Alegre: L\&PM, 1999.

TIRO, Porfírio. Isagoge: Introdução às Categorias de Aristóteles. São Paulo: Attar, 2002.

Data de Registro: $12 / 05 / 08$

Data de Aceite: 18/06/08 